\title{
SOME OBSERVATIONS ON THE GROWTH OF CHILDREN
}

BY

\author{
G. M. ALLEN-WILlIAMS, M.D., D.P.H. \\ (From the Institute of Social Medicine, Oxford)
}

The factors influencing the health and growth of the child during the first five years of life are still only partly understood. The School Medical Service has expanded considerably since it was first begun in 1907, and side by side with it has grown up a health organization for the care of mothers and infants. These services were at first largely concerned with the detection and correction of defects, but latterly researches on nutrition and other aspects of child hygiene have given a new significance to their work, and preventive or constructive medicine has been increasingly emphasized. The care of the child in the years between infancy and school age has, however, received little attention up till now, and the healthy child in this formative period can scarcely be said to have been studied in detail. One reason for this is that the majority of children in this age group do not remain under close and continuous medical supervision unless they are ill or crippled, so that doctors have small opportunity for consecutive studies of unimpaired growth and development.

Physical and other characteristics are determined in part by heredity, in part by maternal health and efficiency, and in part by nutrition and environment. The relative importance of each of these factors in the early years is difficult to assess, and there are few accepted standards of comparison available for children between birth and five years old. Here, as with adults, medicine has tended to base too many of its 'normal' standards on observations made on patients.

Data. The following study was undertaken with a view to assessing physical development at the several ages in respect of the more important dimensions in children up to five years of age, and to show by means of averages the natural rates of growth of trunk and limbs. Such a scheme must necessarily entail observations on a large number of children, and the wartime day nurseries offered an opportunity for examinations of healthy children in the required age group, while entailing the minimum of interference with their normal routine, and of inconvenience to the parents. The investigation was preliminary to a more detailed continuous study of health, growth, and sickness in the preschool child in all social groups and starting from the first weeks of life, and it provided experience in the technique of the measurements that are now being employed in the major survey.

The investigation was based on 465 children between the ages of a few weeks and five years, who were resident in the day nurseries of the City of Oxford during the period January to March, 1944. The number of infants at 0-6 months and at 6-12 months was much too small for adequate statistical analyses and thus, in the subsequent tables, only the average measurements for these two groups are recorded. The period under 12 months was divided into these two component parts because other investigators have asserted that there is a spurt in growth in the latter part of the first year of life.

Some measure of social selection was inevitable. For the most part, the parents of the children were representative of the Registrar-General's Social Class (according to occupation) III. In this Class, and in Classes II and IV, general standards are probably higher in Oxford than in a mainly industrial city. Nutritional advantages have been uniformly improved during the war period by the special provisions for mothers and infants.

Methods. Among the children examined, four (0-84 per cent.) were found on clinical examination to show a marked abnormality. There was one case of congenital spastic diplegia; one child with rickets; one mentally defective child; and one undernourished 'behaviour problem' child. These children were excluded from the tables. Two children had a previous history of conditions satisfactorily treated: one case of bilateral congenital dislocation of the hips, and one case of 'heart trouble.' Neither showed any abnormal physical sign. These children are included in the tables.

Franzen (1929) has shown that measurements of the weight and height alone are not satisfactory for nutritional assessment. The skeletal dimensions, especially the chest and hip measurements, are of importance, and, to a lesser degree, the development of the muscular and subcutaneous tissues. Franzen and Palmer (1934) recommend measurements of arm girth, chest depth, and width of pelvis as suitable for nutritional assessment. Their measurements were made in conjunction with a clinical examination on schoolchildren over six years old, and normal tables of reference were constructed. By means of these the undernourished children could be detected with more certainty and agreement than on clinical grounds alone.

In taking measurements such as these observers made, much depends on the co-operation of the child, which, after school age is attained, is reasonably good. Under five years old, however, cooperation of the child is a very variable factor. In the present study it was found necessary to select measurements which could be made with ease and quickness without tiring or boring the child, and 
which would indicate the skeletal dimensions and the development of the muscular and subcutaneous tissues at the various ages. Chest and arm measurements were found to be too difficult to make with any accuracy in young children. After a good deal of experiment, the following observations, and a clinical examination of the child, were made in each case:

Weight.

Crown-rump length, or ' sitting height.'

Length of lower limb.

Circumference of calf.

Circumference of head.

Antero-posterior and transverse diameters of the head.

Width of pelvis.

All measurements were made by one observer, and accuracy was checked by repeating measurements on the same child at various sessions.

WEIGHT. The machines were checked each time before use, and the children were weighed clothed only in a vest.

CROWN-RUMP LENGTH. This measurement was taken with the child lying supine and straight on a flat table, with the crown of the head against a smooth, flat surface, perpendicular to the table. The child's hips were flexed to a right angle by an assistant, who supported the legs with the knees bent to keep the pelvis flat on the table. A T-square was placed across the table against the child's buttocks, and the distance in centimetres from the crown of the head to the buttocks was taken.

LENGTH OF LOWER LIMB. This measurement was taken with a steel tape measure. The upper end of the great trochanter was palpated, and the distance in centimetres from this point to the tip of the external malleolus, down the lateral side of the leg, was measured.

Circumference OF THE CALF. This measurement was taken with a flexible steel tape-measure over the belly of the gastrocnemius. The leg was measured from the head of the fibula to the external malleolus, and the junction of the upper one-third and lower two-thirds of the leg was marked. At this point the circumference of the calf was taken with the legs relaxed, and the feet in the position of rest. The tape measure was pulled tight so that its surface lay flush with the skin, but without indenting the subcutaneous tissues.

CIRCUMferenCE OF THE HEAD. The tape-measure was passed round the head over the parietal and occipital eminences.

ANTERO-POSTERIOR AND TRANSVERSE DIAMETERS OF THE HEAD. These measurements were taken with a pair of steel callipers: the first from the glabella to the most prominent part of the occipital tuberosity; and the second between the most prominent parts of the parietal eminences.

WIDTH OF PELVIS. The intercristal diameter was taken with the child lying supine. Callipers were applied on the outer edge and at the widest part of the iliac crests.

Results of measurements. Tables $1 \mathrm{~A}$ and 1B give the mean values of the somatometric observations according to age and sex. As is to be expected, the mean value for each variable increases with age, but not in a uniform manner. The table would appear to indicate that in the latter part of the first year of life there is a spurt in growth in each variable, the magnitude of which can be more accurately indicated by the percentage than by the difference between the absolute values; but it must be stressed that the numbers examined in this agegroup were too small to permit of any dogmatism. The percentage increase in successive age periods is shown in table 2.

There is a general indication thatthe rate of increase drops with age more regularly for some measurements than for others. This is particularly true of sitting height. In the first half year its increase is 11.89 per cent. for males, and 12.85 per cent. for females; at approximately 2 years the ratios are 7.44 per cent. and 9.00 per cent. respectively; in the final age-group the rate of increase for males and females drops to 4.40 per cent: and 4.96 per cent.

A comparison of tables $1 \mathrm{~A}$ and $1 \mathrm{~B}$, summarized in table 3, shows the difference between the sexes at each age period.

In most instances the mean values for all measurements in all age-groups are greater among the males than among the females, with the exception of the period 6-12 months, when in six out of the eight variables considered (the weight, all three head measurements, the width of the pelvis, and the circumference of the calf), the female value is the

TABLE 1A.-MALES

AVERAGE MEASUREMENTS ACCORDING TO AGE

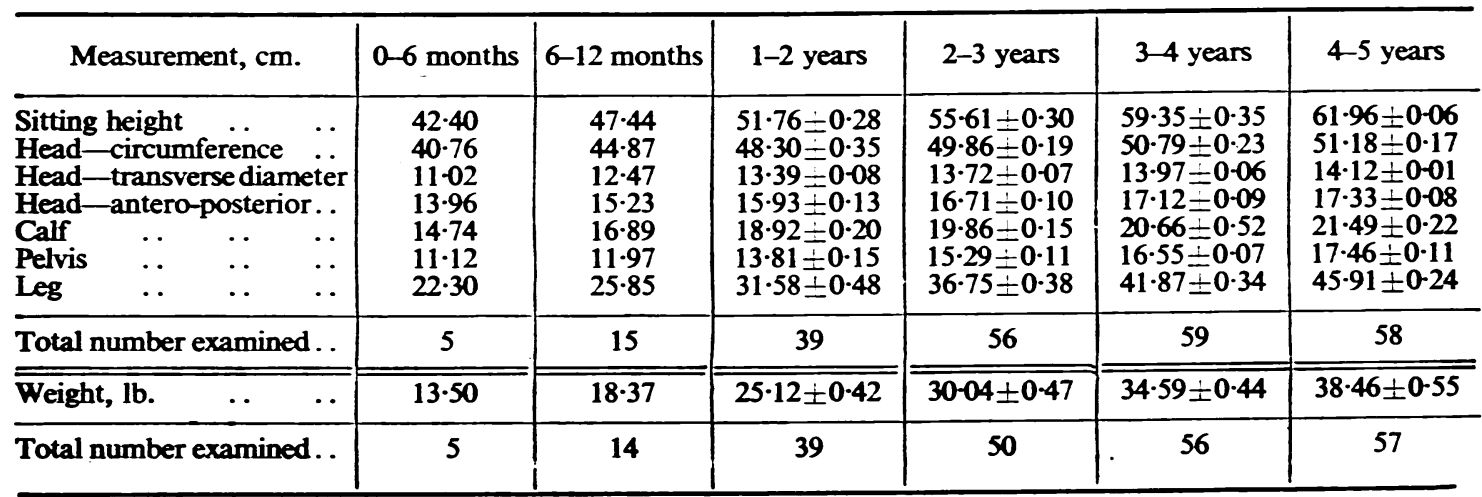


TABLE 1B.-Females AVERAGE MEASUREMENTS ACCORDING TO AGE

\begin{tabular}{|c|c|c|c|c|c|c|c|c|}
\hline \multicolumn{3}{|c|}{ Measurement, cm. } & $0-6$ months & 6-12 months & 1-2 years & $2-3$ years & 3-4 years & $4-5$ years \\
\hline \multicolumn{3}{|c|}{$\begin{array}{l}\text { Sitting height } \text {.. } \\
\text { Head-circumference . } \\
\text { Head-transverse diameter } \\
\text { Head-antero-posterior.. }\end{array}$} & $\begin{array}{l}40-86 \\
39 \cdot 64 \\
10-89 \\
13 \cdot 47 \\
14 \cdot 13 \\
10 \cdot 18 \\
21 \cdot 61 .\end{array}$ & $\begin{array}{l}46 \cdot 11 \\
45 \cdot 00 \\
12 \cdot 75 \\
15 \cdot 25 \\
17 \cdot 66 \\
12 \cdot 36 \\
25 \cdot 36\end{array}$ & $\begin{array}{l}50.89 \pm 0.36 \\
46.98 \pm 0.22 \\
13.04 \pm 0.08 \\
15.73 \pm 0.09 \\
18.36 \pm 0.19 \\
13.55 \pm 0.58 \\
32.09 \pm 0.41\end{array}$ & $\begin{array}{l}55 \cdot 47 \div 0.34 \\
48 \cdot 83 \pm 0.18 \\
13.57=0.10 \\
16.40=0.11 \\
20.18 \div 0.21 \\
15 \cdot 17=0.13 \\
38.26=0.93\end{array}$ & $\begin{array}{l}58 \cdot 84=0.32 \\
49.64=0.18 \\
13.71 \pm 0.07 \\
16.66=0.10 \\
20.86=0.37 \\
16.19=0.12 \\
42.08=0.33\end{array}$ & $\begin{array}{l}61 \cdot 76 \pm 0.48 \\
50 \cdot 24 \pm 0.86 \\
13 \cdot 73 \pm 0-07 \\
16 \cdot 90 \pm 0.10 \\
21 \cdot 82 \pm 0 \cdot 21 \\
17 \cdot 36 \pm 0.13 \\
45 \cdot 92 \pm 0.36\end{array}$ \\
\hline \multicolumn{3}{|c|}{ Total number examined } & 9 & 11 & 35 & 49 & 71 & 54 \\
\hline \multicolumn{2}{|c|}{ Weight, lb. } & . & $12 \cdot 25$ & $19 \cdot 58$ & $23 \cdot 79 \pm 0.47$ & $29 \cdot 66 \pm 0.56$ & $34 \cdot 38=0.49$ & $38 \cdot 50 \pm 0 \cdot 82$ \\
\hline \multicolumn{3}{|c|}{ Total number examined } & 8 & 11 & 33 & 42 & 65 & 51 \\
\hline
\end{tabular}

TABLE 2

PERCENTAGE INCREASE IN GROWTH AT SUCCESSIVE AGES

\begin{tabular}{|c|c|c|c|c|c|c|c|c|c|c|}
\hline & & & & & Sex & $\begin{array}{c}6-12 / 0-6 \\
\text { months }\end{array}$ & $1-2 / \frac{1}{2}-1$ years & $2-3 / 1-2$ years & $3-4 / 2-3$ years & $4-5 / 3-4$ years \\
\hline $\begin{array}{l}\text { Sitting } \\
\text { Head- } \\
\text { Head- } \\
\text { Head- } \\
\text { Calf } \\
\text { Pelvis } \\
\text { Leg } \\
\text { Weight }\end{array}$ & $\begin{array}{l}\text { ceight } \\
\text { circumt } \\
\text { transve } \\
\text { antero- } \\
\ldots \\
\ldots \\
\ldots \\
\ldots\end{array}$ & $\begin{array}{c}\cdots \\
\text { feren } \\
\text { pose }\end{array}$ & $\begin{array}{c}\cdots \\
\cdots \\
\text { met }\end{array}$ & $\begin{array}{c}\ldots \\
\ldots \\
\ldots \\
\text { aeter } \\
\ldots\end{array}$ & $\begin{array}{l}\mathbf{M} \\
\mathbf{F} \\
\mathbf{M} \\
\mathbf{F} \\
\mathbf{M} \\
\mathbf{F} \\
\mathbf{M} \\
\mathbf{F} \\
\mathbf{M} \\
\mathbf{F} \\
\mathbf{M} \\
\mathbf{F} \\
\mathbf{M} \\
\mathbf{F} \\
\mathbf{M} \\
\mathbf{F}\end{array}$ & $\begin{array}{r}11 \cdot 89 \\
12 \cdot 85 \\
10.08 \\
13 \cdot 52 \\
13 \cdot 16 \\
17 \cdot 08 \\
9 \cdot 10 \\
13.05 \\
14 \cdot 59 \\
24 \cdot 98 \\
7.64 \\
21 \cdot 41 \\
15.92 \\
17.35 \\
36.07 \\
59 \cdot 84\end{array}$ & $\begin{array}{r}9 \cdot 11 \\
10 \cdot 37 \\
7 \cdot 64 \\
4 \cdot 40 \\
7 \cdot 38 \\
2 \cdot 27 \\
4 \cdot 60 \\
3 \cdot 15 \\
12 \cdot 02 \\
3 \cdot 96 \\
15 \cdot 37 \\
9 \cdot 62 \\
22 \cdot 17 \\
26 \cdot 54 \\
36 \cdot 74 \\
21 \cdot 50\end{array}$ & $\begin{array}{r}7 \cdot 44 \\
9 \cdot 00 \\
3 \cdot 32 \\
3.94 \\
2.46 \\
4 \cdot 06 \\
4.90 \\
4 \cdot 26 \\
4 \cdot 97 \\
9 \cdot 91 \\
10 \cdot 72 \\
11.95 \\
16.37 \\
19 \cdot 23 \\
19 \cdot 59 \\
24.67\end{array}$ & $\begin{array}{r}6 \cdot 73 \\
6.08 \\
1.87 \\
1.66 \\
1.82 \\
1.03 \\
2.45 \\
1.59 \\
4.03 \\
3.36 \\
8.24 \\
6 \cdot 72 \\
13.93 \\
9.98 \\
15.15 \\
15.91\end{array}$ & $\begin{array}{r}4.40 \\
4.96 \\
0.77 \\
1.21 \\
1.07 \\
0.15 \\
1.23 \\
1.44 \\
4.02 \\
4.60 \\
5 \cdot 50 \\
7.23 \\
9.65 \\
9.13 \\
11.19 \\
11.98\end{array}$ \\
\hline
\end{tabular}

TABLE 3

DIFFERENCES BETWEEN THE AVERAGE MEASUREMENTS OF MALES AND FEMALES ACCORDING TO AGE

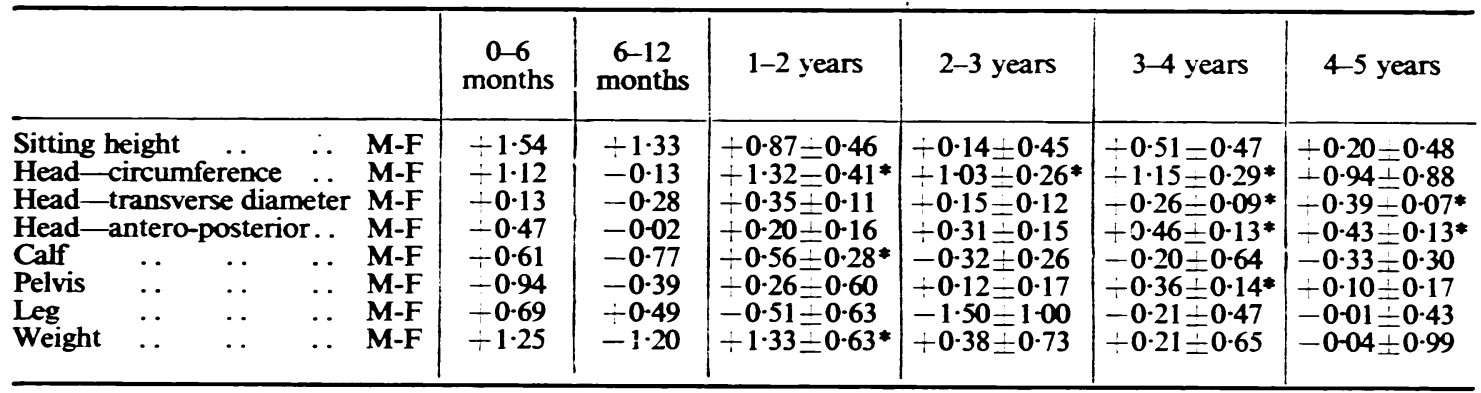

* The values marked with an asterisk are significantly different.

greater. This advantage is maintained only in the length of the lower limb after the first twelve months.

Baldwin (1921) made an extensive study of growth in children up to adolescence. He found that the greatest increase in length took place in the first year of life, and that, on the average, in the preschool period, boys were heavier and longer than girls. Meredith and Boynton (1937) agree with these findings, and also show that, in measurements of the limbs, males have the advantage over females. They found that in both sexes the annual percentage increase in growth was greatest in the first, third, and sixth years. Hill and Magee (1938) studied the increase in weight and length in infants during the first year of life, and concluded that the 
TABLE 4

CORRELATION COEFFICIENTS BETWEEN VARIOUS MEASUREMENTS

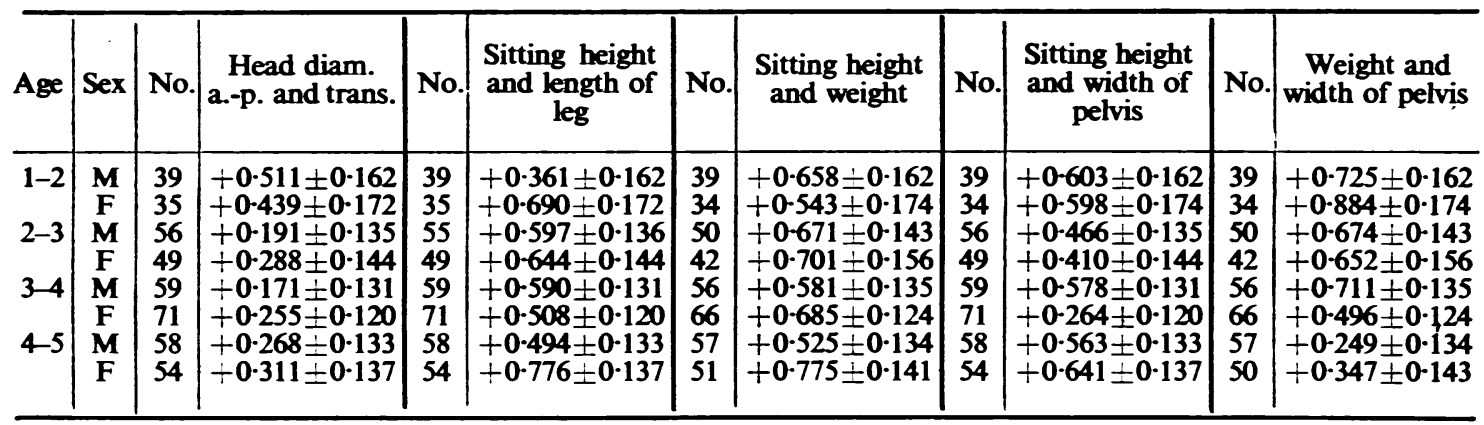

absolute and relative gains in weight drop with length and age; males are 6 per cent. to 9 per cent. heavier and 2 per cent. to 3 per cent. longer than females; and the greatest increase in length takes place at 9-10 months old. None of these authors found any significant difference in growth between the sexes during the pre-school period.

Correlation between variables. It is generally recognized that there is a fair degree of correlation between the dimensions of somatometric variables in adults, but the extent of such a relationship in children under five has not been extensively studied. It was, therefore, desirable to ascertain the correlations between some of the variables in this age period. The results are given in table 4, which shows the correlations between: (a) anteroposterior and transverse diameters of the head; (b) sitting height and length of lower limb; sitting height and weight; sitting height and width of pelvis; and (c) weight and width of pelvis.

As is to be expected, the correlations are all positive in sign, but vary in size at the various ages. There is little evidence of a definite correlation between the antero-posterior and transverse diameters of the head in either sex, except at 1-2 years, when the correlations are significant for both males $(+0.511 \pm 0.162)$ and females $(+0.439 \pm 0 \cdot 172)$. The association between sitting height and weight is the most consistent, as in both sexes the coefficients are greater than 0.5 , and in females of 4-5 years the value is as high as $+0.775 \pm 0.141$. The correlation of pelvic measurements with both sitting height and weight is of interest. For children under 4 years, the pelvic measurement is more closely related to weight than to sitting height, but above this age the reverse is apparent. The correlation between weight and the width of the pelvis declines with increasing age, with one exception. This is among males of 3-4 years, where the correlation is $+0.711 \pm 0.135$. Among females the correlation falls from $+0.884 \pm 0.174$ at $1-2$ years, to $+0.347 \pm 0.143$ at 4-5 years. No other pair of associated variables shows this decline with increasing age. Although there is a fairly high positive correlation between each pair of variables (weight, sitting height, and width of pelvis), it is impossible to be certain that the size of the crude coefficient represents the true relation between them, as physical characteristics are interrelated. Before the basic connexion between any pair can be shown, it is necessary to eliminate the influence of other variables in the relationship. For example, weight and width of pelvis are highly correlated; but each of these is also correlated with sitting height. What, then, is the relation between weight and width of pelvis, when the sitting height is held constant? This can be discovered by means of partial correlation coefficients, which are shown in table 5, together with the $Z$ transformation and its significance.

The table shows the important relationship between weight and width of pelvis in children 1-4 years old. Here the values are highly significant,

TABLE 5

PARTIAL CORRELATION COEFFICIENTS BETWEEN VARIOUS MEASUREMENTS

\begin{tabular}{|c|c|c|c|c|}
\hline Age & Sex & $\begin{array}{l}\text { Partial } \\
\text { correlations }\end{array}$ & $\mathbf{Z}$ & $\begin{array}{c}\text { Standard } \\
\text { Error }\end{array}$ \\
\hline \multirow[t]{2}{*}{$1-2$} & $\mathbf{M}$ & $\begin{array}{l}\mathrm{r} 13 \cdot 2=0.2434 \\
\mathrm{r} 23 \cdot 1=0.5466\end{array}$ & $\begin{array}{l}0.248 \\
0.614\end{array}$ & $\begin{array}{l} \pm 0 \cdot 169 \\
\pm 0 \cdot 169\end{array}$ \\
\hline & $\mathbf{F}$ & $\begin{array}{l}r 13 \cdot 2=0.2995 \\
\mathrm{r} 23 \cdot 1=0.8291\end{array}$ & $\begin{array}{l}0.309 \\
1 \cdot 185\end{array}$ & $\begin{array}{l} \pm 0.182 \\
\pm 0.182\end{array}$ \\
\hline \multirow[t]{2}{*}{$2-3$} & $\mathbf{M}$ & $\begin{array}{l}\mathrm{r} 13 \cdot 2=0.0251 \\
\mathrm{r} 23 \cdot 1=0.5507\end{array}$ & $\begin{array}{l}0.250 \\
0.619\end{array}$ & $\begin{array}{l} \pm 0.147 \\
\pm 0.147\end{array}$ \\
\hline & $\mathbf{F}$ & $\begin{array}{l}\mathrm{r} 13 \cdot 2=-0.0870 \\
\mathrm{r} 23 \cdot 1=0.5604\end{array}$ & $\begin{array}{r}-0.087 \\
0.634\end{array}$ & $\begin{array}{l} \pm 0.162 \\
\pm 0.162\end{array}$ \\
\hline \multirow[t]{2}{*}{$3-4$} & $\mathbf{M}$ & $\begin{array}{l}\mathrm{r} 13 \cdot 2=0.2886 \\
\mathrm{r} 23 \cdot 1=0.5634\end{array}$ & $\begin{array}{l}0.297 \\
0.638\end{array}$ & $\begin{array}{l} \pm 0.139 \\
\pm 0.139\end{array}$ \\
\hline & $\mathbf{F}$ & $\begin{array}{l}\mathrm{r} 13 \cdot 2=-0 \cdot 1198 \\
\mathrm{r} 23 \cdot 1=0.4485\end{array}$ & $\begin{array}{r}-0.120 \\
0.483\end{array}$ & $\begin{array}{l} \pm 0.127 \\
\pm 0.127\end{array}$ \\
\hline \multirow[t]{2}{*}{$4-5$} & $\mathbf{M}$ & $\begin{array}{l}\mathrm{r} 13 \cdot 2=0.5244 \\
\mathrm{r} 23 \cdot 1=-0.0662\end{array}$ & $\begin{array}{r}0.738 \\
-0.066\end{array}$ & $\begin{array}{l} \pm 0.137 \\
\pm 0.137\end{array}$ \\
\hline & $\mathbf{F}$ & $\begin{array}{l}\mathrm{r} 13 \cdot 2=0.6278 \\
\mathrm{r} 23 \cdot 1=-0.3090\end{array}$ & $\begin{array}{r}0.738 \\
-0.319\end{array}$ & $\begin{array}{l} \pm 0.146 \\
\pm 0.146\end{array}$ \\
\hline
\end{tabular}

1-Sitting height.

2-Weight.

3-Width of pelvis. 
whereas the values of $Z$ for sitting height and size of pelvis are less than twice their standard errors. In children of 4-5 years the reverse is true. Weight in relation to width of pelvis is less important than the association between sitting height and width of pelvis.

\section{Summary and Conclusions}

Although the data relating to infants under one year in this investigation are few in number, they would appear to suggest that the greatest period of growth occurs in the latter half of the first year of life.

Up to 5 years old growth in the male is, on the whole, greater-but not significantly greaterthan in the female.

The highest degree of relationship among the variables observed is found between sitting height and weight. Up to 4 years the width of the pelvis is more closely correlated with the weight than with the sitting height, but this alters with age, so that at 4-5 years the width of the pelvis is more closely related to the sitting height.

It is a pleasure to record my thanks to Dr. G. C. Williams, Medical Officer of Health, Oxford, for the facilities which made this enquiry possible; to Dr. Archer, Assistant Medical Officer of Health, for permission to make observations in the day nurseries; and to the staff of the nurseries for their willing co-operation. I am also indebted to Dr. W. T. Russell for statistical assistance, and to Professor J. A. Ryle for advice and criticism.

\section{REFERENCES}

Baldwin, B. T. (1921). Univ. Iowa Studies in Child Welfare, 1, 1

Franzen, R. (1929). Amer. Child Hlth. Ass. Publ. Schl. Hlth. Mon., No. 2. , and Palmer, A. (1934). Ibid., 12, 138.

Hill, A. B., and Magee, H. E. (1938). Med. Off., 60, 157.

Meredith, H. V., and Boynton, B. (1937). Hum. Biol., 9, 366. 